Research Article

\title{
Comparison of tremor induced by valproate and lithium in bipolar disorder using a hand steadiness tester
}

\author{
Mohua Sengupta ${ }^{1}$, Prathama Guha ${ }^{2}$, Prithwijit Banerjee ${ }^{1}$, Suhrita Paul ${ }^{1}$, \\ Ritasman Baisya ${ }^{3}$, Kaveri Bhattacharya ${ }^{2}$
}

${ }^{1}$ Department of Pharmacology, Medical College, Kolkata-713104, West Bengal, India,

${ }^{2}$ Department of Psychiatry, Medical College, Kolkata-713104, West

Bengal, India,

${ }^{3}$ Final Year MBBS, Medical

College, Kolkata-713104, West

Bengal, India

Received: 3 December 2013

Accepted: 15 December 2013

*Correspondence to:

Dr. Mohua Sengupta,

Email: senguptamohua@yahoo.co.in

(C) 2014 Sengupta M et al. This is an open-access article distributed under the terms of the Creative Commons Attribution Non-Commercial License, which permits unrestricted non-commercial use, distribution, and reproduction in any medium, provided the original work is properly cited.

\begin{abstract}
Background: Quantitative measurement of valproate and lithium induced tremor using hand steadiness tester and their comparison in bipolar disorder. Methods: 200 newly diagnosed patients of bipolar disorder were randomly allocated into two equal groups receiving lithium (300mg twice daily) and sodium valproate (500 $\mathrm{mg}$ twice daily) after they fulfilled the inclusion / exclusion criteria of the study. 87 patients from Lithium group and 93 from Valproate completed the study. Hand Tremor was assessed quantitatively at $0,6,12,18$ and 24 weeks using hand steadiness tester. Anxiety level of the study subjects was assessed to be insignificant using a standardized anxiety scale. Final data was assessed after 24 weeks by using Stat Calc and Z test. $P$ value $<0.05$ was considered to be significant.

Results: No significant difference was found in terms of the development and transition of tremor induced by valproate and lithium $(\mathrm{p}=0.22)$. However more men developed tremor with lithium when compared with females $(p<0.05)$ and the mean age of patients who developed tremor appeared to be significantly higher in lithium group $(54.7 \pm 3.9)$ than valproate $(39.6 \pm 5.1)$.

Conclusions: Tremor of hands is a common side effect of lithium and valproate treatment. Timely, objective assessment of onset and extent of tremor has always remained a challenge to the clinicians. Hand Steadiness tester is a simple, portable, inexpensive, non-invasive instrument that can be used to ascertain the development and transition of tremor in a quantitative manner. This would guide the clinicians as when to intervene for better management of such tremors.
\end{abstract}

Keywords: Tremor, Lithium, Valproate, Hand Steadiness Tester

\section{INTRODUCTION}

Bipolar disorder (BPD) is a common psychiatric illness characterized by unpredictable swings in mood from mania (hypomania) to depression. ${ }^{1}$ The manic and depressive symptoms of bipolar disorder are usually controlled by a monotherapy or combination of medications. The "gold standard" mood stabilizer is lithium, ${ }^{2}$ another commonly used drug being sodium valproate. $^{3}$
Lithium is one of the oldest and most frequently prescribed drugs available for the treatment of adult bipolar mania and depression but with serious side effects including weight gain, thirst, nausea, and hand tremors. Tremor is the most frequent reason given by patients for discontinuing lithium. ${ }^{4}$ On the other hand, sodium valproate is one of the few drugs available that has been proven effective in treating rapid cycling bipolar and mixed states patients. It is also approved for the treatment of mania. Stomach cramps, diarrhoea, hair loss, nausea, and unusual weight loss or gain and tremors are some of the common side effects of valproate. 
Tremors often present as involuntary, oscillating movements of muscles located in various parts of the body including head, face, vocal cords, arms, trunk, and legs. In general, most tremors commonly occur in the hands leading to embarrassment and difficulty performing activities of daily living. ${ }^{5}$ Thus tremor has been an adverse effect of both Lithium and Valproate that can be incapacitating and result in significant social and occupational impairment. Incidence and severity of tremor may widely vary in different patient settings. ${ }^{6}$

The frequency of tremor can be approximated by physicians' observation and subsequent grading which is often subjective. However, till date to best of our knowledge, there is no head to head quantifiable clinical comparison available for Valproate and Lithium regarding tremor in patients of bipolar disorder. In this comparative clinical study, an attempt has been made to estimate the incidence as well as the severity of tremor induced by the above drugs. Tremor has been quantified by using Hand steadiness Tester, a simple tool which can be operated conveniently in the out-patients setup. Being non-invasive and cost effective in nature, this machine provides fair patient compliance.

\section{METHODS}

The present study was undertaken jointly by the departments of Pharmacology and Psychiatry of Medical College Kolkata during January 2012 to June 2013. Prior permission of Institutional Ethics Committee was obtained. Two hundred and twenty patients (18 -60 years) of either sex attending Psychiatry OPD and newly diagnosed with Bipolar disorder were preliminary screened for the study. Diagnosis was made by a consultant Psychiatrist using the Structured Clinical Interview for DSM IV (SCID IV). A total of 200 patients were randomly allocated into Group receiving lithium (300mg twice daily) and Group B receiving sodium valproate (500 mg twice daily) as monotherapy after they fulfilled the inclusion / exclusion criteria of the study. 87 in Group A (lithium) and 93 in Group B (valproate) completed the study. Written Informed consent was taken in their own language before the subjects were enrolled for the study.

\section{Selection criteria}

\section{a) Inclusion criteria}

1. Age 18 to 60 year

2. Absence of significant anxiety as measured by STAI scale

3. Monotherapy with either lithium or valproate

4. Willing to give Informed written consent

5. Free from obvious tremor (using hand steadiness Tester) while entering the study.

\section{b) Exclusion criteria}

1. Any history of substance use in the last six months.

2. Presence of any neurological illness

3. History of traumatic brain injury

4. Mentally retarded patients

\section{Study tool}

Hand steadiness tester: an electronic device for quantitative measurement of hand tremor. It has a range of holes with diameters ranging from $2.5 \mathrm{~mm}$ to $12 \mathrm{~mm}$. We standardized the methodology by asking 30 normal healthy volunteers to test their hand steadiness and found that 28 of them succeeded in keeping the probe in $4.5 \mathrm{~mm}$ diameter hole for at least 30 seconds without touching the rim of the hole. So, this was considered as normal baseline. Therefore, 5 holes of diameter $4.5 \mathrm{~mm}, 5 \mathrm{~mm}$, $6.5 \mathrm{~mm}, 8 \mathrm{~mm}$ and $12 \mathrm{~mm}$ were selected and named as A to $\mathrm{E}$ in ascending order for purpose of our study.

- STAI (State Trait Anxiety Inventory in standardized Bengali version) to exclude patients with symptoms of anxiety.

- Case record form

- Informed consent form

\section{Study technique}

At 0 week, while starting therapy with either of the drugs, tremor was assessed with Hand Steadiness Tester (HST) and subjects with no obvious evidence of tremor

(Grade A) were included in the study. STAI (State Trait Anxiety Inventory) was used to exclude patients with symptoms of anxiety. The Patients of both the groups were evaluated for tremor at 6, 12, 18, 24 weeks. Each patient was asked to keep the probe inside the hole for at least 30 seconds without touching the rim.

\section{Statistical analysis}

The collected data are entered in the excel sheet in tabulated form. Stat calc was used and $\mathrm{Z}$ test done. $\mathrm{P}<$ 0.05 was considered to be significant.

\section{RESULTS}

Out of 200 patients enrolled for the study (100 in each group) 87 receiving lithium and 93 receiving sodium valproate i.e. 180 completed the study. Baseline characteristics at enrollment of study are given in (Table 1). The two groups were comparable in terms of age and sex and mean duration of complaints.

Development of tremor was noted at subsequent visits and also transition of tremor grade from milder to severe with time was taken into account. No significant difference in both the groups was observed (Table 2). 
Table 1: Baseline characteristics of subjects who completed the study.

\begin{tabular}{|lll|}
\hline Characteristics & Lithium & Valproate \\
\hline Total subjects (n) & 87 & 93 \\
\hline Male & $52(59.77 \%)$ & $54(58.06 \%)$ \\
\hline Female & $35(41.23 \%)$ & $39(42.94 \%)$ \\
\hline Mean age \pm SD (years) & $39.1 \pm 16.4$ & $36.8 \pm 18.3$ \\
\hline $\begin{array}{l}\text { Mean duration of } \\
\text { complaints in months }\end{array}$ & 6.16 & 6.8 \\
\hline
\end{tabular}

Table 2: Development of tremor and its transition in both groups after 24 weeks.

\begin{tabular}{|llll|}
\hline Tremor transition & LI $(\mathbf{n = 8 7})$ & VAL $(\mathbf{n = 9 3})$ & P value \\
\hline Tremor Development & $42(48.3 \%)$ & $32(34.4 \%)$ & 0.22 \\
\hline 1 grade (A - B ) & $23(26.4 \%)$ & $21(22.5 \%)$ & 0.81 \\
\hline 2 grades $($ A - C ) & $11(12.6 \%)$ & $7(7.5 \%)$ & 0.628 \\
\hline 3 grades A - D ) & $6(6.9 \%)$ & $4(4.3 \%)$ & 0.769 \\
\hline 4 grades (A - E) & $2(2.3 \%)$ & 0 & 0.043 \\
\hline
\end{tabular}

While considering the first appearance of tremor in both the groups, it was observed that earlier onset of tremor was observed in lithium group, although the difference in both the groups was comparable and not statistically significant (Table 3).

\section{Table 3: First appearance of tremor in both groups} after 24 weeks.

\begin{tabular}{|llll|}
\hline Weeks & LI $(\mathbf{n = 8 7})$ & VAL $(\mathbf{n = 9 3 )}$ & P value \\
\hline 6 weeks & $11(12.6 \%)$ & $4(4.3 \%)$ & 0.641 \\
\hline 12 weeks & $9(10.3 \%)$ & $13(14 \%)$ & 0.796 \\
\hline 18 weeks & $18(20.6 \%)$ & $8(8.6 \%)$ & 0.451 \\
\hline 24 weeks & $4(4.6 \%)$ & $7(7.5 \%)$ & 0.706 \\
\hline
\end{tabular}

When the mean age of patients developing tremor in both groups were noted, it was observed that mean age of development of tremor in the lithium group was significantly higher than in the valproate group (Table 4).

\section{Table 4: Mean age of development of tremor in both groups after 24 weeks.}

\begin{tabular}{|lll|}
\hline $\begin{array}{l}\text { Study } \\
\text { group }\end{array}$ & $\begin{array}{l}\text { Mean age } \\
\text { (years) }\end{array}$ & $\begin{array}{l}\text { Mean age of subjects who } \\
\text { developed tremor (years) }\end{array}$ \\
\hline Lithium & $39.1 \pm 16.4$ & $54.7 \pm 7.9$ \\
\hline Valproate & $36.8 \pm 18.3$ & $39.6 \pm 11.5$ \\
\hline
\end{tabular}

It was also noted that in lithium group more men developed tremor when compared females $(\mathrm{p}<0.05)$ where as in valproate group the gender difference was comparable and not significant statistically $(\mathrm{p}=0.296)$ (Table 5).

In lithium group, $13 \%$ did not complete the study while $7 \%$ of patients receiving valproate dropped out. Loss to follow up was the most frequent cause of discontinuation followed by tremor \& diarrhoea in lithium group and nausea and diarrhoea in the valproate group (Table 6).

\section{Table 5: Gender distribution of development of tremor in both groups after 24 weeks.}

\begin{tabular}{|llllll|}
\hline Study & Male & $\begin{array}{l}\text { Males } \\
\text { who } \\
\text { develop } \\
\text { ed } \\
\text { tremor }\end{array}$ & Female & $\begin{array}{l}\text { Females } \\
\text { who } \\
\text { developed } \\
\text { tremor }\end{array}$ & $\begin{array}{l}\text { P } \\
\text { value }\end{array}$ \\
\hline Lithium & 52 & $\begin{array}{l}28 \\
(66.7 \%)\end{array}$ & 35 & $14(33.3 \%)$ & 0.043 \\
\hline Valproate & 54 & $\begin{array}{l}19 \\
(59.4 \%)\end{array}$ & 39 & $14(40.6 \%)$ & 0.296 \\
\hline
\end{tabular}

Table 6: Reasons for discontinuation of therapy.

\begin{tabular}{|c|c|c|}
\hline & $\begin{array}{l}\text { Lithium } \\
(\mathrm{n}=100)\end{array}$ & $\begin{array}{l}\text { Valproate } \\
(\mathrm{n}=\mathbf{1 0 0})\end{array}$ \\
\hline Loss to follow up & 7 & 3 \\
\hline Tremor & 3 & 0 \\
\hline Nausea & 0 & 2 \\
\hline Diarrhoea & 3 & 2 \\
\hline
\end{tabular}

\section{DISCUSSION}

Tremors often accompany nervous system degenerative diseases such as Parkinson's disease or they may emerge as a consequence of exposure to neurotoxins ${ }^{7}$ high potency neuroleptics ${ }^{8}$ and mood stabilisers. ${ }^{9}$ Tremor often causes social embarrassment and is a handicap when performing daily tasks; it is also often a reason to stop taking treatment. ${ }^{10}$

Development of a fine hand tremor by patients initiating treatment with lithium is a well-known and anticipated side effect. It has been estimated that $53 \%$ of patients develop tremor during the first week of lithium therapy, yet tremor is present in only $4 \%$ of patients who have taken lithium for one to two years. Estimates of tremor severe enough to impair functioning or be socially embarrassing range from $10-65 \% .^{10}$ Tremor may occur in patients taking therapeutic doses of lithium and is also an early sign of toxic lithium levels ${ }^{11}$. Beta blockers are often utilized as a first-line pharmacologic intervention for lithium tremor ${ }^{12}$. Risk factors identified with increasing the risk of lithium tremor include increasing age, male sex, high serum lithium levels, concurrent antidepressant medications (particularly tricyclic antidepressants) and neuroleptic medications, excessive caffeine intake, personal or family history of tremor, presence of alcoholism, and associated anxiety. ${ }^{9,11}$ No evidence supports an association between the occurrence of lithium tremor and the duration of lithium treatment. ${ }^{13}$ Fine hand tremor occurring as a side effect of lithium therapy should be distinguished from the coarser hand tremor which indicates lithium toxicity. ${ }^{11}$ 
Valproate is one of the most prescribed antiepileptic medications frequently used in treatment of Bipolar disorders and is also particularly associated with tremors. Incidence of valproate-induced tremor is thought to occur in $6-45 \%$ of patients. ${ }^{14}$ It is the most common neurologic adverse event observed with valproate. Approximately $25 \%$ of patients taking valproate are found to develop a tremor within 3-12 months of initiating therapy. ${ }^{5}$ The occurrence of tremor is found to be more associated with valproate dose than plasma concentration $^{14}$ Beta blockers are often utilized as a firstline pharmacologic intervention for valproate tremor. ${ }^{15}$

Tremors also arise in healthy individuals under conditions of stress or fatigue and thus may not signal the presence of disease. Traditional assessments of tremor severity often employ several tasks such as handwriting, finger-tonose testing and drawing Archimedes spirals. ${ }^{16} \mathrm{~A}$ standard method for measuring and quantifying tremor characteristics would have a positive effect on all tremor related research. The present study was done with a simple, portable machine- Hand Steadiness Tester by means of which we could easily assess the degree of tremor in a quantitative manner. The results of the study indicate that there is no significant difference in transition and development of tremor induced by valproate and lithium $(p>0.05)$ during the study period of 24 weeks. Interestingly, there was a male predisposition to the incidence of tremor in the group receiving lithium $(p<0.05)$ which substantiates the earlier observations. ${ }^{9,11,13}$ Another observation was that the mean age of patients developing tremor in the lithium group was significantly higher than in the valproate group; a finding corroborated by other studies. $9,11,13$

\section{CONCLUSION}

Tremor of hands is a common side effect of lithium and valproate treatment. Timely, objective assessment of onset and extent of tremor has always remained a challenge to the clinicians. Hand Steadiness tester is a simple, portable, inexpensive, non-invasive instrument that can be conveniently used in OPD settings to ascertain the development and transition of tremor in a quantitative manner. This would guide the clinicians as when to intervene for better management of such tremors.

Funding: No funding sources Conflict of interest: None declared

Ethical approval: Approval was taken from the institutional ethics committee

\section{REFERENCES}

1. Victor I Reus. Mental disorders. In Fauci, Braunwald, Kasper, Haiser, Longo, Jameson,
Loscalzo. Harrison's Principles of Internal Medicine. $17^{\text {th }}$ Edition. New York: Mc Graw Hill; 2008: 27102723.

2. Poolsup N, Li Wan Po A, de Oliveira IR. Systematic overview of lithium treatment in acute mania. J Clin Pharm Ther. 2000;25 (2):139-56.

3. Tripathi KD. Drugs used in mental illness: Antipsychotic and antimanic drugs. In Essentials of medical pharmacology, $6^{\text {th }}$ Edition. Jaypee Brothers Medical Publishers (P) Ltd.; 2008: 423-438.

4. N.Ferrier, S.P.Tyrer \& A.J.Bell. Lithium therapy. Advances in Psychiatric Treatment. 1995;1:102-10.

5. Arbaizar B, Gómez-Acebo I, Llorca J. Postural induced-tremor in psychiatry. Psychiatry clin neurosci. 2008;62(6):638-45.

6. Canning JE, Burton S, Hall B. Lithium and Valproate-Induced Tremors. Ment Health Clin. 2012;1(7):19.

7. Beuter, A., Edwards, R., Degeoffroy A., Margler, D. Andhundell, K. Quantification of neuromotor function for detection of the effects of manganese. Neurotoxicity. 1999;20:355-66.

8. Caligiuri, M. P., Jeste, D. V., and Lacro, J. P. Drug induced movement disorders in the elderly: epidemiology and treatment recommendations. Drugs and Aging. 2000;17:363-84.

9. Gelenberg AJ and Jefferson JW. Lithium Tremor. Journal of Clinical Psychiatry. 1995;56:283 -7.

10. Gelenberg AJ, Kane JM, Keller MB et al. Comparison of standard and low serum levels of lithium for maintenance treatment of bipolar disorder. N. Engl. J. Med. 1989;321:489-93.

11. Carroll JA, Jeffersion JW, Greistjh. Treating tremor induced by lithium. Hospital and Community Psychiatry. 1987;38:1280-8.

12. Van Putten T. Lithium-induced disabling tremor. Psychosomatics Canadian Medical Association Journal. 1976;114:619-24.

13. Vestergaard P. Clinically important side effects of long-term lithium treatment: A review. Acta Psychiatr Scan. 1983; supp305.

14. Rinnerthaler M, Luef G, Mueller J, Seppi K, Wissel J, Trinka E, Bauer G, Poewe W. Computerized tremor analysis of valproate-induced tremor: a comparative study of controlled-release versus conventional valproate. Epilepsia. 2005:46(2):320-3.

15. Karas BJ, Wilder BJ, Hammond EJ, Bauman AW. Treatment of valproate tremors. Neurology. 1983;33(10):1380-2.

16. Elble RJ, Koller WC. Tremor. Baltimore: The Johns Hopkins University Press; 1990.

doi:10.5455/2319-2003.ijbcp20140219

Cite this article as: Sengupta M, Guha P, Banerjee P, Paul S, Baisya R, Bhattacharya K. Comparison of tremor induced by valproate and lithium in bipolar disorder using a hand steadiness tester. Int J Basic Clin Pharmacol 2014;3:151-4. 